\title{
Research Paper: \\ Cyclosomatostatin-Induced Catalepsy in the Aged Wistar Rats: Inhibition by Nicotine
}

\author{
Ilya D. Ionova ${ }^{1 *}$, Irina I. Pushinskaya² \\ 1. Centre on Theoretical Problems in Physical and Chemical Pharmacology, Russian Academy of Sciences, Moscow, Russia. \\ 2. Timpharm LTD, Moscow, Russia.
}

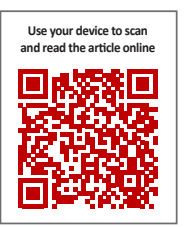

Citation: lonova ID, Pushinskaya II. Cyclosomatostatin-Induced Catalepsy in the Aged Wistar Rats: Inhibition by Nicotine. Avicenna J of Neuropsychophysiology. 2017; 4(2):65-70. http://dx.doi.org/10.32598/ajnpp.4.2.65

Funding: See Page 69

(c) Copyright: The Author(s)

Article info:

Received: 10 July 2016

Accepted: 05 December 2016

Available Online: 01 May 2017

Keywords:

Aging, Somatostatin, Nicotine,

Catalepsy, Parkinson disease

\begin{abstract}
Background: Recently, it has been found that Cyclosomatostatin (CSST) induces Catalepsy, a State Similar to extrapyramidal dysfunctions in Parkinson disease. The sensitivity of CSST-induced catalepsy to clinically effective antiparkinsonian agents is unknown. Epidemiological studies have documented an inverse association between parkinsonism and tobacco smoking that suggests an antiparkinsonian activity of nicotine. To evaluate the similarity between human illness and CSSTinduced catalepsy, we studied the sensitivity of this model to nicotine.
\end{abstract}

Materials and Methods: The experiments were conducted on 27- to 28-month-old male Wistar rats. To determine the cataleptogenic doses of CSST, this drug $(0.5,2$, and $10 \mu \mathrm{g})$ was injected intracerebroventricularly. Nicotine $(0.1,0.4$, and $1 \mathrm{mg} / \mathrm{kg}$ ) was given subcutaneously. Catalepsy was defined as an increased period of immobility in the bar test. All groups consisted of 8 animals.

Results: CSST $(10 \mu \mathrm{g})$ increased period of immobility compared with the controls $(\mathrm{P}<0.01)$. Nicotine $(0.4$ and $1 \mathrm{mg} / \mathrm{kg})$ inhibited this effect $(P<0.05)$.

Conclusion: CSST-induced catalepsy in Wistar rats can be reduced by nicotine. These data support the validity of this behavioral response as a model of human extrapyramidal dysfunctions.

\section{Introduction}

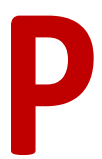

arkinson disease is characterized by the degeneration of dopaminergic neurons in the substantia nigra. Akinesia and other extrapyramidal motor disorders are the main features of this disease [1-3]. Age is the biggest risk factor for the development of Parkinson disease [4]; However, tobacco smoking decreases the incidence of the illness [5]. Although various therapeutic strategies were proposed in the past decades, none of them has stopped the disease progression.

A number of animal models are currently in use to identify new potential antiparkinsonian agents. Neurotoxic models use toxins that causes reversible or irreversible injury to dopaminergic neurons. Genetic models are based on genetic mutations that either selectively disrupt nigral neurons or simulates mutations

\section{*Corresponding Author:}

Ilya D. Ionova, PhD

Address: Centre on Theoretical Problems in Physical and Chemical Pharmacology, Russian Academy of Sciences, Moscow, Russia.

E-mail: newrology@yandex.ru 
found in familial parkinsonism [6]. Meanwhile, presently no model uses factors characteristic of Idiopathic Parkinson Disease (IPD). As it seems, such models may be of special significance in the search for novel antiparkinsonian drugs.

One of the IPD-associated abnormalities is dropping the brain levels of somatostatin [7]. These changes may be of pathogenic importance as somatostatin can modulate dopaminergic neurotransmission. In fact, exogenous somatostatin increases dopamine release from neurons [8-10]. Elevation of the brain somatostatin concentrations potentiates dopamine-dependent contraversive pivoting behavior in rats [11]. Alternatively, a drop in brain somatostatin can reduce the response of animals to dopaminergic agonists, apomorphine and amphetamine [12]. Thus, somatostatin seems to be a stimulatory factor for dopaminergic system. Given this, a decrease in brain somatostatin activity in IPD might inhibit brain dopamine-dependent mechanisms and cause or aggravate extrapyramidal dysfunctions.

We have recently simulated a decrease in brain somatostatin activity in Wistar rats $[7,13]$ using intracerebral injections of Cyclosomatostatin (CSST), an antagonist of somatostatin receptors [14]. It has been found that CSST induces cataleptic response. Catalepsy, an abnormal behavior that resembles bradykinesia and postural rigidity in IPD, is often linked to an inhibition of central dopaminergic activity $[15,16]$ and thereby is used as a model of extrapyramidal dysfunctions. In our experiments, the CSST effect was observed in aged rats [13]. Thus, CSSTinduced catalepsy displayed the age-dependence effect similar to that of IPD. Apparently, this property of the model supports its validity.

An important feature of the model is its responsiveness to clinically effective agents [17]. One of the potential antiparkinsonian agents may be nicotine since epidemiological studies have shown a lower risk of IPD in tobacco smokers [5]. The influence of nicotine on dopaminergic neurotransmission and catalepsy has been previously examined. Nicotine increased dopamine release from neurons in vitro [18] and in vivo [19]; however, acute administration of nicotine potentiated rather than inhibited catalepsy induced by haloperidol [20] and some other neuroleptics [21, 22]. Nicotine in vitro protected dopaminergic neurons against a range of toxic insults [23]; however, in vivo this drug can increase the susceptibility of nigral neurons to toxic injury [24].

The present study aimed to evaluate the validity of somatostatin antagonist-induced catalepsy as a model of IPD-associated motor dysfunctions. For this purpose, we assessed the responsiveness of CSST-induced catalepsy to nicotine, an agent with presumed clinical antiparkinsonian activity.

\section{Materials and Methods}

\subsection{Animals}

The experiments were conducted on 27 to 28-monthold male Wistar rats. The average lifespan of these rats is approximately 25 months [25]. Thus, the animals in our study are old. Rats were housed four per cage in a well-ventilated colony room having a 12:12 h light/dark cycle (lights on at 7:00 AM) and temperature of $22^{\circ} \mathrm{C}$. The animals received standard laboratory rat chow and tap water ad libitum. The animals were adapted to these conditions for a minimum of two weeks before the experiments. The experiments were started by randomly dividing animals into groups of 8 each.

\subsection{Drugs and doses}

Cyclo (7-aminoheptanoyl-Phe-D-Trp-Lys-Thr[Bzl]) (cyclosomatostatin), (-)-nicotine hydrogen tartrate salt (nicotine), ( \pm )-ketamine hydrochloride (ketamine), xylazine hydrochloride (xylazine) were purchased from Sigma-Aldrich (Street Louis, MO, USA). Gentamicin sulfate (Krka, Slovenia) and polysporin triple antibiotic ointment (Johnson \& Johnson Inc.) were used as well. $\operatorname{CSST}(0.5,2$, and $10 \mu \mathrm{g})$ and nicotine $(0.1,0.4$, and 1 $\mathrm{mg} / \mathrm{kg}$ ) were administered intracerebroventricularly and subcutaneously, respectively. CSST was dissolved in sterile artificial cerebrospinal fluid and nicotine in sterile saline [26]. The doses were chosen based on the literature and previous experiments in our laboratory $[7,13,27]$. Nicotine was administered $15 \mathrm{~min}$ prior to the injection of CSST.

\subsection{Implantation of an intracerebral cannula}

The surgical operations were performed as described [28]. Before surgery each rat was injected with gentamicin sulfate, $5 \mathrm{mg} / \mathrm{kg}$ intramuscularly. The animal was anaesthetized with intraperitoneal administration of ketamine and xylazine (75 and $7.5 \mathrm{mg} / \mathrm{kg}$ i.p. respectively) and placed in a stereotaxic apparatus. A hole was drilled into the skull and a stainless steel guide cannula (22 gauge, 15- $\mathrm{mm}$ long) lowered into the right lateral ventricle using the following stereotaxic coordinates: $\mathrm{ML}=-1.6 \mathrm{~mm}, \mathrm{DV}=-3.6 \mathrm{~mm}$, and $\mathrm{AP}=-0.8 \mathrm{~mm}$ from bregma. Cannula was fixed to the skull with jeweler screws embedded in dental acrylic cement. 
After placement, this cannula was sealed with a sterile obturator. Skin in the area of dissection was treated with polysporin triple antibiotic ointment. Ten days after implantation of the guide cannula, the experiments were conducted in the experimental room wherein the environmental conditions were similar to those in the animal room. Leakage of the cerebrospinal fluid from the cannula during its implantation was used as the criterion for proper actions [29]. Cannula placements were also verified postmortem by sectioning through the brain.

\subsection{Intracerebral injection procedure}

Microinjection of CSST solution or vehicle into the lateral ventricle was made as described [28, 30]. Briefly, we used a needle connected by polyethylene tubing to a $10 \mu \mathrm{L}$ syringe. After removal of the obturator, the needle was protruded $1 \mathrm{~mm}$ beyond the cannula tip and solution $(10 \mu \mathrm{L})$ was injected over 30s. After the injection, the needle remained in place for 30 s before withdrawal to prevent injection fluid backflow through the cannula.

\subsection{Evaluation of catalepsy}

Catalepsy in rodents is a state of temporal immobility characterized by failure to correct an externally imposed awkward position [31, 32]. Bar test was used as a method for quantitative evaluation of catalepsy. Each rat was placed with its forelimbs on a wooden bar (7.5 $\mathrm{cm}$ above the table surface, diameter of $1.5 \mathrm{~cm}$ ). Animal's hind paws rested on the table surface. The length of time(s) the animal maintained the initial position was measured $[33,34]$. In the first two daily sessions, the rats were adapted to the catalepsy procedure [32].

On the third day, the experimental session was performed. To complete one experimental test, the animal is placed on the bar three times and the mean stay of these three periods is the outcome of one test [33]. The time measurements were performed by an experimenter blinded to the group assignment. On each session, these measurements were performed 60, 120, 180 and $240 \mathrm{~min}$ after administration of CSST with the animals being kept in their home cages between tests. Sessions started at 9:30 AM. Catalepsy was defined as a statistically significant $(P<0.05)$ increase in immobility duration.

\subsection{Outline of experiments}

Two separate experiments were performed. In experiment I, the animals received different doses of CSST. The control animals received either no intervention (control $\# 1$ ) or vehicle instead of CSST (control \#2). The most ef- fective cataleptogenic dose of CSST was used in further studies. Experiment II aimed to evaluate the influence of nicotine on CSST-induced catalepsy. The rats were treated by the drug at different doses; the control animals received either no intervention (control \#3), or vehicle instead of CSST (control \#4), or nicotine $(1.0 \mathrm{mg} /$ $\mathrm{kg}$ ) alone (control \#5).

\subsection{Statistical analysis}

Results are presented as mean \pm standard error of the mean. Normality of the distribution of all variables was checked by one-sample Kolmogorov-Smirnov test. Because the study data were not distributed normally, we used 2-way repeated measures ANOVA on ranks and nonparametric Tukey test. Any differences showing a $\mathrm{P}<0.05$ were considered statistically significant.

\section{Results}

In experiment I, intervention-free and vehicle-treated rats (control groups \#1 and \#2) were immobile for 8-16 s (Table 1). These results are generally consistent with data obtained in male Wistar rats by other authors [35]. CSST at the dose of $0.5 \mu \mathrm{g}$ caused no catalepsy (no differences with control group \#1 and 2, P>0.05) (Table 1). In contrast, CSST at the doses of $2 \mu \mathrm{g}$ and $10 \mu \mathrm{g}$ produced cataleptic behavior. The effect was seen at all time points after the injection of cataleptogen (Table 1). These findings basically replicated our previous results $[7,13]$. The most effective dose, $10 \mu \mathrm{g}$, was used in the next stage of the research.

In experiment II, the animals received nicotine at the dose of $1 \mathrm{mg} / \mathrm{kg}$ (control \#5) demonstrated no catalepsy (mean immobile duration did not differ from those of intervention-free or vehicle-treated rats, $\mathrm{P}>0.05$ ) (Table 2). At the same time, nicotine dose-dependently inhibited CSST-induced cataleptic response. The dose of 0.1 $\mathrm{mg} / \mathrm{kg}$ had no effect whereas animals treated with nicotine at the doses of 0.4 and $1.0 \mathrm{mg} / \mathrm{kg}$ exhibited attenuated $(P<0.05)$ response to CSST (Table 2$)$. Nicotine with doses of $0.4 \mathrm{mg} / \mathrm{kg}$ and $1.0 \mathrm{mg} / \mathrm{kg}$ were equally effective for suppressing catalepsy (mean immobility durations in these groups did not differ significantly, $\mathrm{P}>0.05$ ).

As can be seen in Table 2, dose-effect relationship for nicotine is obviously nonlinear and, in large doses, could be characterized as "a plateau effect". Thus, further increase in the dose of nicotine may not result in more pronounced inhibition of catalepsy. 
Table 1. Response of Wistar rats to CSST

\begin{tabular}{|c|c|c|c|c|}
\hline \multirow{2}{*}{ Drug } & \multicolumn{4}{|c|}{ Immobile Duration at Various Time Points After Intracerebral Injection of Vehicle or CSST } \\
\hline & $60 \mathrm{Min}$ & 120 Min & 180 Min & 240 Min \\
\hline No intervention (control \#1) & $13.1 \pm 2.14$ & $12.8 \pm 1.97$ & $13.4 \pm 2.09$ & $13.1 \pm 1.95$ \\
\hline Vehicle (control \#2) & $12.2 \pm 1.84$ & $11.8 \pm 1.71$ & $12.6 \pm 1.78$ & $10.9 \pm 1.56$ \\
\hline CSST (0.5 $\mu \mathrm{g})$ & $12.9 \pm 2.19$ & $14.4 \pm 2.30$ & $13.1 \pm 2.10$ & $12.3 \pm 2.11$ \\
\hline CSST ( $2 \mu \mathrm{g})$ & $25.4 \pm 4.58^{*}$ & $23.8 \pm 3.27^{*}$ & $24.5 \pm 3.40^{* *}$ & $22.9 \pm 3.18^{*}$ \\
\hline CSST $(10 \mu g)$ & $34.0 \pm 6.46^{*}$ & $33.3 \pm 5.49^{*}$ & $31.7 \pm 5.24^{*}$ & $32.5 \pm 5.34^{*}$ \\
\hline
\end{tabular}

AJNPP

Results are presented as Mean \pm standard error of the mean $(n=8) ;{ }^{*} P<0.01$ : Difference from vehicle-injected controls; ${ }^{* *} P<0.05$ : Difference from vehicle-injected controls

\section{Discussion}

At the present study, nicotine inhibited CSST-induced catalepsy (Table 2). At the same time, a lower risk for IPD among tobacco smokers suggests that nicotinesensitive mechanism may be implicated in the development of IPD. Thus, our model and human illness seem to share common feature, i.e. the responsiveness to nicotine. This similarity supports the validity of CSSTinduced catalepsy as a model of parkinsonism.

The mechanism of nicotine anticataleptic effect in this model is obscure. Apparently, this effect may, at least in part, be attributable to the ability of nicotine to enhance dopamine release from nigral neurons [18,
19]. Given the relation between development of catalepsy and brain dopaminergic deficiency $[15,16]$, such a mechanism seems well founded. However, nicotine failed to inhibit catalepsy induced by haloperidol [20, $36,37]$. Similarly, nicotine did not influence some other rat behaviors associated with dopamine deficiency, particularly, amphetamine-induced rotational behavior [38] and exploratory asymmetric forelimb use [39]. It is possible that the nicotine-induced stimulation of the neuronal dopamine release per se may be insufficient to effectively potentiate dopaminergic neurotransmission and thereby inhibit catalepsy.

In all likelihood, the mechanism of nicotine effect may go beyond stimulation of dopamine release from neu-

Table 2. Influence of nicotine on the response to $10 \mu \mathrm{g}$ of CSST

\begin{tabular}{|c|c|c|c|c|}
\hline \multirow{2}{*}{ Drugs } & \multicolumn{4}{|c|}{ Immobile Duration at Various Times After Intracerebral Injection of Vehicle or CSST } \\
\hline & 60 Min & 120 Min & 180 Min & 240 Min \\
\hline No intervention (control \#3) & $13.9 \pm 2.14$ & $11.6 \pm 1.97$ & $12.4 \pm 1.97$ & $10.8 \pm 1.93$ \\
\hline Vehicle (control \#4) & $14.3 \pm 1.99$ & $13.6 \pm 1.91$ & $12.0 \pm 1.68$ & $13.1 \pm 1.83$ \\
\hline Nicotine $(1.0 \mathrm{mg} / \mathrm{kg}$, control \#5) & $13.6 \pm 2.11$ & $14.3 \pm 2.07$ & $13.1 \pm 1.96$ & $-12.7 \pm 2.03$ \\
\hline CSST & $35.8 \pm 5.72^{* *}$ & $34.1 \pm 5.79^{* *}$ & $32.3 \pm 5.17^{* *}$ & $35.0 \pm 5.89^{* *}$ \\
\hline CSST+nicotine $(0.1 \mathrm{mg} / \mathrm{kg})$ & $28.6 \pm 4.29^{* a}$ & $26.4 \pm 4.22^{* a}$ & $25.3 \pm 4.05^{* * a}$ & $26.1 \pm 4.18^{* a}$ \\
\hline CSST+nicotine (0.4 mg/kg) & $23.6 \pm 3.30 * \#$ & $25.1 \pm 3.07^{* a}$ & $21.4 \pm 2.99^{* \#}$ & $22.6 \pm 3.16^{* \#}$ \\
\hline CSST+nicotine (1.0 mg/kg) & $21.9 \pm 3.04^{*} \#$ & $22.3 \pm 3.12^{* \#}$ & $19.2 \pm 2.70^{* \#}$ & $20.9 \pm 2.87^{* \#}$ \\
\hline
\end{tabular}

AJNPP

Results are presented as Mean \pm standard error of the mean $(n=8) ;{ }^{*} P<0.05$ : Difference from vehicle-treated animals; ${ }^{* *} P<0.01$ : Difference from vehicle-treated animals; ${ }^{\#}<<0.05$ : Difference from animals treated with CSST alone; ${ }^{a}$ No significant difference from animals treated with CSST alone $(\mathrm{P}>0.05)$ 
rons. Nicotine was found to enhance brain levels of somatostatin [40] that may contribute to the inhibition of CSST-induced catalepsy. Concurrently, nicotine might indirectly stimulate CSST-induced catalepsy. This drug, as was shown previously, can enhance release of endogenous histamine from histaminergic fibers [41]. Histamine, in turn, can potentiate CSST-induced catalepsy in Wistar rats [7]. Thus, non-linear dose-effect relationship for nicotine in the present study may reflect the combination of two opposite effects of nicotine.

\section{Conclusion}

Whatever the mechanism of nicotine, the available data show common features in CSST-induced catalepsy and IPD. In fact, this model and human disease are associated with the same brain abnormality i.e. a decrease in somatostatin activity, demonstrate a similar age-dependence, and are responsive to nicotine intervention or tobacco smoking. These clear parallels between our model and human disease characteristics could facilitate future translational research.

\section{Ethical Considerations}

\section{Compliance with ethical guidelines}

Rats were housed four per cage in a well-ventilated colony room having a 12:12 h light/dark cycle (lights on at 7:00 AM) and temperature of $22^{\circ} \mathrm{C}$. The animals received standard laboratory rat chow and tap water ad libitum.

\section{Funding}

This research did not receive any specific grant from funding agencies in the public, commercial, or not-forprofit sectors.

\section{Conflict of interest}

The authors declare no conflict of interest.

\section{Acknowledgments}

Ilya D. lonova is indebted to his long-standing mentors, Professor Igor Efimovich Kovalev and Professor Lev Aramovich Piruzyan. The researcher highly appreciate technical support of Timpharm Ltd (Moscow, Russia).

\section{References}

[1] Hornykiewicz O. Biochemical aspects of Parkinson's disease. Neurology. 1998; 51(2 Suppl 2):S2-9. [DOI:10.1212/WNL.51.2 Suppl_2.S2] [PMID]

[2] Thomas B, Beal MF. Parkinson's disease. Human Molecular Genetics. 2007; 16(R2):R183-94. [DOI:10.1093/hmg/ddm159]

[3] Magrinelli F, Picelli A, Tocco P, Federico A, Roncari L, Smania $\mathrm{N}$, et al. Pathophysiology of motor dysfunction in Parkinson's disease as the rationale for drug treatment and rehabilitation. Parkinson's Disease. 2016; 2016:9832839 [DOI:10.1155/2016/9832839]

[4] Hindle JV. Ageing, neurodegeneration and Parkinson's disease. Age Ageing. 2010; 39(2):156-61. [DOI:10.1093/agee ing/afp223] [PMID]

[5] Ascherio A, Schwarzschild MA. The epidemiology of Parkinson's disease: Risk factors and prevention. The Lancet Neurology. 2016; 15(12):1257-72. [DOI:10.1016/S1474-4422(16)30230-7]

[6] Gubellini P, Kachidian P. Animal models of Parkinson's disease: An updated overview. Revue Neurologique. 2015; 171(11):750-61 [DOI:10.1016/j.neurol.2015.07.011] [PMID]

[7] Ionov ID, Turgeneva ZA. Histamine potentiates cyclosomatostatin-induced catalepsy in old rats. Avicenna Journal of NeuroPsychoPhysiology. 2015; 2(2):16-9. [DOI:10.17795/ajnpp-31238]

[8] Chesselet MF, Reisine TD. Somatostatin regulates dopamine release in rat striatal slices and cat caudate nuclei. Journal of Neuroscience. 1983; 3(1):232-6. [DOI:10.1523/JNEUROO SCI.03-01-00232.1983

[9] Hathway GJ, Emson PC, Humphrey PP, Kendrick KM. Somatostatin potently stimulates in vivo striatal dopamine and gamma-aminobutyric acid release by a glutamate-dependent action. Journal of Neurochemistry. 1998; 70(4):1740-9. [DOI:10.1046/ j.1471-4159.1998.70041740.x] [PMID]

[10] Hathway GJ, Humphrey PP, Kendrick KM. Somatostatin induces striatal dopamine release and contralateral turning behaviour in the mouse. Neuroscience Letters. 2004; 358(2):127-31. [DOI:10.1016/j.neulet.2003.09.056] [PMID]

[11] Ikeda H, Kotani A, Koshikawa N, Cools AR. Somatostatin receptors in the nucleus accumbens modulate dopamine-dependent but not acetylcholine-dependent turning behaviour of rats. Neuroscience. 2009; 159(3):974-81. [DOI:10.1016/j.neuroe science.2009.01.053] [PMID]

[12] Lee N, Radke JM, Vincent SR. Intra-cerebral cysteamine infusions attenuate the motorresponse to dopaminergic agonists. Behavioural Brain Research. 1988; 29(1-2):179-83. [DOI:10.1016/0166-4328(88)90065-4]

[13] Ionov ID, Pushinskaya II. Somatostatin antagonist induces catalepsy in the aged rat. Psychopharmacology. 2013; 227(2):273-6. [DOI:10.1007/s00213-012-2961-0] [PMID]

[14] Fries JL, Murphy WA, Sueiras-Diaz J, Coy DH. Somatostatin antagonist analog increases $\mathrm{GH}$, insulin, and glucagon release in the rat. Peptides. 1982; 3(5):811-4. [DOI:10.1016/01969781(82)90020-1]

[15] Crocker AD, Hemsley KM. An animal model of extrapyramidal side effects induced by antipsychotic drugs: Relationship with D2 dopamine receptor occupancy. Progress in Neuro-Psy- 
chopharmacology \& Biological Psychiatry. 2001; 25(3):573-90 [DOI:10.1016/S0278-5846(00)00176-7]

[16] Wadenberg ML, Soliman A, VanderSpek SC, Kapur S Dopamine D2 receptor occupancy is a common mechanism underlying animal models of antipsychotics and their clinical effects. Neuropsychopharmacology. 2001; 25(5):633-41. [DOI:10.1016/S0893-133X(01)00261-5]

[17] Duty S, Jenner P. Animal models of Parkinson's disease: A source of novel treatments and clues to the cause of the disease. British Journal of Pharmacology. 2011; 164(4):1357-91. [DOI:10.1111/j.1476-5381.2011.01426.x] [PMID] [PMCID]

[18] Teng L, Crooks PA, Sonsalla PK, Dwoskin LP. Lobeline and nicotine evoke $[3 \mathrm{H}]$ overflow from rat striatal slices preloaded with $[3 \mathrm{H}]$ dopamine: Differential inhibition of synaptosomal and vesicular $[3 \mathrm{H}]$ dopamine uptake. Journal of Pharmacology and Experimental Therapeutics. 1997; 280(3):1432-44. [PMID]

[19] Lecca D, Shim I, Costa E, Javaid JI. Striatal application of nicotine, but not of lobeline, attenuates dopamine release in freely moving rats. Neuropharmacology. 2000; 39(1):88-98. [DOI:10.1016/S0028-3908(99)00085-4]

[20] Sanberg PR, Emerich DF, Mohamed M, Shipley MT, Zanol MD Cahill DW, et al. Nicotine potentiation of haloperidol-induced catalepsy: Striatal mechanisms. Pharmacology Biochemistry and Behavior. 1993; 46(2):303-7. [DOI:10.1016/0091-3057(93)90357-Y]

[21] Zarrindast MR, Haeri-Zadeh F, Zarghi A, Lahiji P. Nicotine potentiates sulpiride-induced catalepsy in mice. Journal of Psychopharmacology. 1998; 12(3):279-82. [DOI:10.1177/02698 8119801200308] [PMID]

[22] Zarrindast MR, Samadi P, Haeri-Rohani A, Moazami N, Shafizadeh $\mathrm{M}$. Nicotine potentiation of morphine-induced catalepsy in mice. Pharmacology Biochemistry and Behavior. 2002; 72(12):197-202. [DOI:10.1016/S0091-3057(01)00754-7]

[23] Quik M, O'Leary K, Tanner CM. Nicotine and Parkinson's disease: Implications for therapy. Movement Disorders. 2008; 23(12):1641-52. [DOI:10.1002/mds.21900] [PMID] [PMCID]

[24] Behmand RA, HarikSI. Nicotine enhances 1-methyl-4-phenyl-1, 2, 3, 6-tetrahydropyridine neurotoxicity. Journal of Neurochemistry. 1992; 58(2):776-9. [DOI:10.1111/j.1471-4159.1992.tb09786.x]

[25] Ooka H, Fujita S, Yoshimoto E. Pituitary-thyroid activity and longevity in neonatally thyroxine-treated rats. Mechanisms of Ageing and Development. 1983; 22(2):113-20. [DOI:10.1016/0047-6374(83)90104-5]

[26] Klein MC, Gertner SB. Studies on the mechanism of the cardiovascular action of central injections of histamine. Neuropharmacology. 1983; 22(9):1109-15. [DOI:10.1016/0028-3908(83)90032-1]

[27] Dyr WA, Koros EL, Bienkowski PR, Kostowski WO. Involvement of nicotinic acetylcholine receptors in the regulation of alcohol drinking in Wistar rats. Alcohol and Alcoholism (Oxford, Oxfordshire). 1999; 34(1):43-7. [DOI:10.1093/alcalc/34.1.43] [PMID]

[28] de Carvalho CR, Hoeller AA, Franco PL, Martini AP, Soares FM, Lin K, et al. The cannabinoid CB2 receptor-specific agonist AM1241 increases pentylenetetrazole-induced seizure severity in Wistar rats. Epilepsy Research. 2016; 127:160-7. [DOI:10.1016/j.eplepsyres.2016.08.011] [PMID]

[29] Antunes-Rodrigues J, McCann SM. Water, sodium chloride, and food intake induced by injections of cholinergic and adrenergic drugs into the third ventricle of the rat brain. Proceedings of the Society for Experimental Biology and Medicine. 1970; 133(4):1464-70. [DOI:10.3181/00379727-133-34713] [PMID]

[30] Crofton JT, Rockhold RW, Share L, Wang BC, Horovitz $\mathrm{ZP}$, Manning M, Sawyer WH. Effect of intracerebroventricular captopril on vasopressin and blood pressure in spontaneously hypertensive rats. Hypertension. 1981; 3(6_pt_2):II-71. [DOI:10.1161/01.HYP.3.6_Pt_2.II-71]

[31] Erzin-Waters C, Muller P, Seeman P. Catalepsy induced by morphine or haloperidol: Effects of apomorphine and anticholinergic drugs. Canadian Journal of Physiology and Pharmacology. 1976; 54(4):516-9. [DOI:10.1139/y76-071] [PMID]

[32] Sanberg PR, Pisa M, Fibiger HC. Kainic acid injections in the striatum alter the cataleptic and locomotor effects of drugs influencing dopaminergic and cholinergic systems. European Journal of Pharmacology. 1981; 74(4):347-57. [DOI:10.1016/0014-2999(81)90054-6]

[33] Dijk S, Krugers HJ, Korf J. The effect of theophylline and immobilization stress on haloperidol-induced catalepsy and on metabolism in the striatum and hippocampus, studied with lactography. Neuropharmacology. 1991; 30(5):469-73. [DOI:10.1016/0028-3908(91)90008-Y]

[34] Kheradmand A, Nayebi AM, Jorjani M, Haddadi R. Effect of WR-1065 on 6-hydroxydopamine-induced catalepsy and IL-6 level in rats. Iranian Journal of Basic Medical Sciences. 2016; 19(5):490-6. [PMID] [PMCID]

[35] Nayebi AM, Rad SR, Saberian M, Azimzadeh S, Samini M. Buspirone improves 6-hydroxydopamine-induced catalepsy through stimulation of nigral 5-HT1A receptors in rats. Pharmacological Reports. 2010; 62(2):258-64. [DOI:10.1016/S1734-1140(10)70264-4]

[36] Emerich DF, Norman AB, Sanberg PR. Nicotine potentiates the behavioral effects of haloperidol. Psychopharmacology Bulletin. 1991; 27(3):385-90. [PMID]

[37] Boye SM, Clarke PB. Enhancement of haloperidol-induced catalepsy by nicotine: An investigation of possible mechanisms. Canadian Journal of Physiology and Pharmacology. 2000; 78(11):88291. [DOI:10.1139/y00-070]

[38] Huang LZ, Parameswaran N, Bordia T, Michael McIntosh J, Quik M. Nicotine is neuroprotective when administered before but not after nigrostriatal damage in rats and monkeys. Journal of Neurochemistry. 2009; 109(3):826-37. [DOI:10.1111/j.14714159.2009.06011.x] [PMID] [PMCID]

[39] Bordia T, Campos C, Huang L, Quik M. Continuous and intermittent nicotine treatment reduces L-3,4- Dihydroxyphenylalanine (L-DOPA)-induced dyskinesias in a rat model of Parkinson's disease. Journal of Pharmacology and Experimental Therapeutics. 2008; 327(1):239-47. [DOI:10.1124/jpet.108.140897] [PMID]

[40] Barrios V, González-Parra S, Arilla E. Acute nicotine administration increases somatostatin content and binding in the rat hypothalamus. Life Sciences. 1992; 51(25):1991-8. [DOI:10.1016/0024-3205(92)90116-7]

[41] Ono J, Yamatodani A, Kishino J, Okada S, Wada H. Cholinergic influence of $\mathrm{K}(+)$-evoked release of endogenous histamine from rat hypothalamic slices in vitro. Methods and Findings in Experimental and Clinical Pharmacology. 1992; 14(1):35-40. [PMID] 